\title{
Acute epiglottitis caused by community-acquired methicillin-resistant Staphylococcus aureus in a healthy infant
}

\section{Jumpei Fujisawa' \\ Tomokazu Mutoh' \\ Kengo Kawamura' \\ Nami Sawada ${ }^{2}$ \\ Daisuke Ono ${ }^{3}$ \\ Tetsuo Yamaguchi ${ }^{3}$ \\ Ichiro Morioka'}

'Department of Pediatrics and Child Health, Nihon University School of Medicine, Tokyo, Japan; ${ }^{2}$ Department of Acute Medicine, Nihon University School of Medicine, Tokyo, Japan; ${ }^{3}$ Department of Microbiology and Infectious Diseases, Toho University School of Medicine, Tokyo, Japan
Correspondence: Ichiro Morioka Department of Pediatrics and Child Health, Nihon University School of Medicine, 30-I, Ooyaguchi, Kamimachi, Itabashi, Tokyo I7386I0, Japan

$\mathrm{Tel}+8 \mathrm{I} 339728 \mathrm{III}$

Fax +8 I 339585744

Email morioka.ichiro@nihon-u.ac.jp
This article was published in the following Dove Press journal: Infection and Drug Resistance

\begin{abstract}
Haemophilus influenzae was the main causative organism for acute epiglottitis in the pre-Haemophilus influenzae type b (Hib) vaccine era. However, with current widespread Hib vaccination, the causative organisms may have changed. Here, we report the case of a healthy infant with acute epiglottitis caused by community-acquired methicillin-resistant Staphylococcus aureus (MRSA). The patient was a healthy 17-day-old male infant without a family history of immunodeficiency syndrome. He had not been started on any vaccines. On the third day of illness, he was diagnosed with acute pharyngitis with exudation on the back of the larynx. Although treatment using cefotaxime was initiated, he showed stridor, difficulty in pronunciation, and cyanosis upon crying on the fourth day. On the fifth day, he was diagnosed with acute epiglottitis by laryngoscopy, which showed a downward spread of the exudation and laryngeal edema. He was intubated and started on artificial respiration. Due to the detection of MRSA from a pharyngeal swab culture, he was treated with vancomycin. His fever disappeared on the first day after admission, and he was extubated on the eighth day after admission. MRSA genome analysis of the patient sample revealed negative Panton-Valentine leukocidin, positive toxic shock syndrome toxin 1, and type IV clone of staphylococcal cassette chromosome mec. This is a first case of acute epiglottitis caused by MRSA with a Panton-Valentine leukocidinnegative and toxic shock syndrome toxin 1-positive staphylococcal cassette chromosome mec type IV clone, which is known as a community-acquired MRSA in Japan. Community-acquired MRSA may be considered a causative organism for acute epiglottitis in the post-Hib vaccine era. Keywords: pre-Haemophilus influenzae type b vaccine era, type IV clone of staphylococcal cassette chromosome mec, Panton-Valentine leucocidin, toxic shock syndrome toxin 1, exudate
\end{abstract}

\section{Introduction}

Acute epiglottitis is a common disease in children aged 1-11 years and initially presents with symptoms such as fever and sore throat, followed by difficulty in swallowing and laborious breathing and stridor as the disease progresses. ${ }^{1,2}$ Because this fatal disease causes sudden airway obstruction due to laryngeal edema, emergency treatment is often required in the pediatric intensive care unit.

In the pre-Haemophilus influenzae type B (Hib) vaccine era, $75 \%-90 \%$ of the cases of acute epiglottitis were caused by $H$. influenzae. ${ }^{2}$ However, in the post-Hib vaccine era, the causative organisms have changed, and the proportion of acute epiglottitis cases caused by Streptococcus pneumoniae and Staphylococcus aureus is increasing in some countries. ${ }^{3,4}$ In Japan, the Hib vaccine was introduced as a voluntary vaccination in 2008 and as an universal vaccination in 2013. With generalization of Hib vaccination 
in Japan, the number of patients affected by Hib has decreased dramatically ${ }^{5}$ and the incidence of epiglottitis due to Hib also should have decreased. Thereafter, Str. pneumoniae or Sta. aureus may have emerged as the main causative organism of acute epiglottitis in Japan. Here, we report the case of an infant with acute epiglottitis caused by Japanese communityassociated (CA)-methicillin-resistant Sta. aureus (MRSA) with written informed consent for publication from the parents of the patient. Ethics committee approved the waiver in this case report, based on the Japanese ethical guideline for clinical research.

\section{Case report}

A healthy 17-day-old male infant without a family history of immunodeficiency syndrome was consulted by his family physician for cough, nasal discharge, and a fever on the third day of illness. He had not started any vaccines because of his age ( $<1$ month). He was diagnosed with acute pharyngitis along with exudation on the back of the larynx. Although cefotaxime treatment was initiated, wheezing, difficulty in vocalizing, and cyanosis on crying were observed on the fourth day. On the fifth day, laryngoscopy revealed a downward spread of exudation and laryngeal edema, which led to diagnosis of acute epiglottitis (Figure 1A, B). Because airway management was required, he was referred to our pediatric intensive care unit and immediately started on artificial respiration.

At the time of admission, the patient's laboratory tests showed the following: white blood cell count $4,700 / \mu \mathrm{L}$ (band cell: 35\%, segmented cell: $31 \%$, eosinophil: 5\%, monocyte: $8 \%$, lymphocyte: $18 \%$, atypical lymphocyte: $3 \%$ ), hemoglobin level $11.1 \mathrm{~g} / \mathrm{dL}$, platelet count $24.4 \times 10^{4} / \mu \mathrm{L}$, and C-reactive protein level $6.65 \mathrm{mg} / \mathrm{dL}$. Other laboratory findings were as follows: serum albumin $2.4 \mathrm{~g} / \mathrm{dL}$, total bilirubin $0.48 \mathrm{mg} / \mathrm{dL}$, sodium $137 \mathrm{mEq} / \mathrm{L}$, potassium $3.3 \mathrm{mEq} / \mathrm{L}$, aspartate aminotransferase $14 \mathrm{U} / \mathrm{L}$, alanine aminotransferase $8 \mathrm{U} / \mathrm{L}$, lactate dehydrogenase $260 \mathrm{IU} / \mathrm{L}$, urea nitrogen 3.9 $\mathrm{mg} / \mathrm{dL}$, and creatinine $0.19 \mathrm{mg} / \mathrm{dL}$. His IgG, IgA, IgM, C3, $\mathrm{C} 4$, and $\mathrm{CH} 50$ levels were within the normal ranges (IgG: $686 \mathrm{mg} / \mathrm{dL}, \mathrm{IgA}: 19 \mathrm{mg} / \mathrm{dL}, \mathrm{IgM}: 52 \mathrm{mg} / \mathrm{dL}, \mathrm{C} 3: 84 \mathrm{mg} / \mathrm{dL}$, C4: $15 \mathrm{mg} / \mathrm{dL}$, and CH50: $32.5 \mathrm{U} / \mathrm{L})$. His arterial blood gas under 1.0 of the fraction of inspired oxygen showed a $\mathrm{pH}$ of 7.428, $\mathrm{pCO}_{2}$ of $42 \mathrm{mmHg}, \mathrm{pO}_{2}$ of $114.0 \mathrm{mmHg}^{\mathrm{HCO}_{3}^{-}}$of $27.2 \mathrm{mmol} / \mathrm{L}$, and base excess of $3.1 \mathrm{mmol} / \mathrm{L}$. Rapid antigen test for respiratory syncytial and adenoviruses was negative

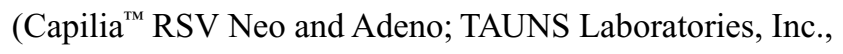
Shizuoka, Japan). MRSA was detected from the posterior nasal cavity swab culture and the pharyngeal swab culture

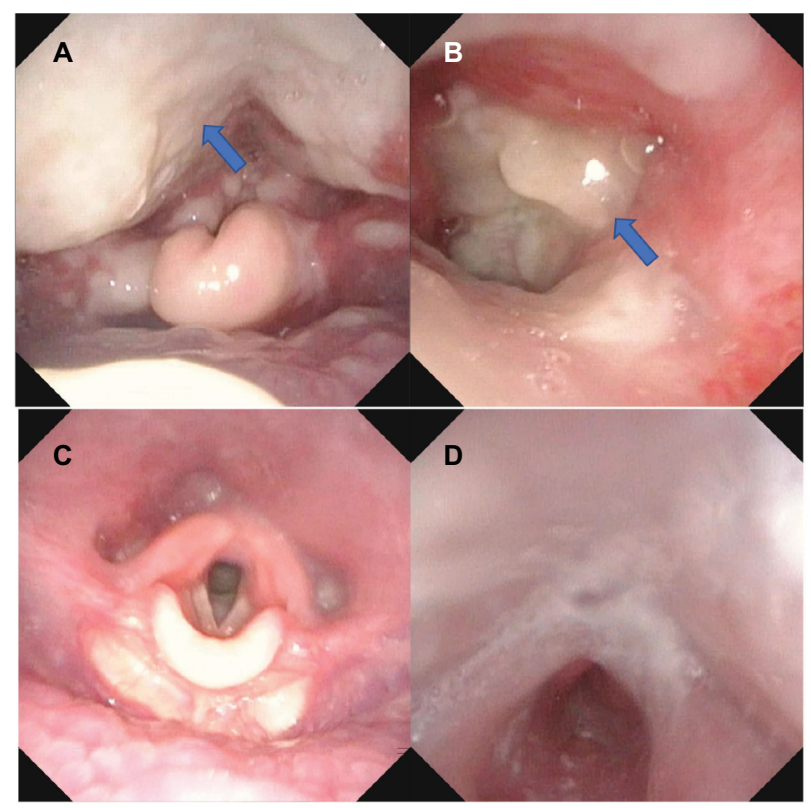

Figure I Laryngoscopic findings.

Notes: (A, B) Laryngoscopic images before intubation. Arrows indicate the exudates. (C, D) Laryngoscopic images after extubation.

at the site attached to the exudate, but skin swab culture and blood culture were negative. Owing to the detection of MRSA, he was treated with vancomycin. The fever disappeared on the first day of admission, and he was extubated on the eighth day of admission. Figure 1C, D shows his laryngoscopic images after extubation. Finally, the patient was discharged on the 18th day of admission.

\section{Identification of MRSA and genome analysis}

Gram staining and culture using blood and chocolate agar were performed to identify the organisms using swabs obtained from the posterior nasal cavity or pharynx of the patient. Because Sta. aureus was detected, the culture using MRSA screen media (CHROMagar ${ }^{\mathrm{TM}}$; Kanto Chemical Co., Inc., Tokyo, Japan) was performed to identify MRSA. Determination of the minimum inhibitory concentration of each antibiotic for the isolated strain was performed using a RAISUS $^{\mathrm{TM}}$ system with the RSMSE panel (Nissui Pharmaceutical Co., Ltd, Tokyo, Japan). The inoculum was adjusted to yield a cell density of $1 \times 10^{5}$ colony-forming units $/ \mathrm{mL}$. The plates were incubated for $18-24$ hours at $35^{\circ} \mathrm{C}$ and then analyzed automatically. Result of the antimicrobial susceptibility test for the isolated strain is shown in Table 1.

Bacterial genomic DNA of the isolated strain was extracted using a DNeasy Blood \& Tissue Kit (Qiagen) with lysostaphin (Wako). Genomic DNA was used as a template for PCR-based screening assays. MRSA SCCmec 
type (I-V) screening was conducted using a PCR-based assay as previously described. ${ }^{6,7} \mathrm{We}$ detected $m e c A$ gene and class B mec gene complex and type $2 \mathrm{ccr}$ gene complex by multiplex-PCR methods. These results indicated that SCCmec type of the isolated strain was type IV. ${ }^{8,9}$ Staphylococcal virulence genes including the Panton-Valentine leukocidin (PVL) gene (luks-pv), two exfoliative toxin (ET) genes (eta and $e t b$ ), and toxic shock syndrome toxin 1 (TSST-1) gene (tst-1) were detected by PCR assay using primers that have been reported previously. ${ }^{10-13}$ The results of the MRSA genome analysis of the patient sample revealed a PVL-negative and TSST-1-positive SCCmec type IV clone (Table 2).

\section{Discussion}

The MRSA genotypes of SCCmec are bacteriologically classified as types I-XIII. ${ }^{14}$ Types I, II, and III are known as hospital-acquired MRSA, and types IV and $\mathrm{V}$ are recognized as CA-MRSA. ${ }^{15,16}$ The PVL-positive SCCmec type IV clone produces a powerful toxin called PVL and is widely detected in the USA and Europe. ${ }^{16}$ Another toxin known as TSST-1 causes neonatal toxic shock syndrome-like exanthematous

Table I Antimicrobial susceptibility test for the isolated strain

\begin{tabular}{|l|l|l|}
\hline Antibiotic & $\begin{array}{l}\text { Minimum inhibitory } \\
\text { concentration }\end{array}$ & Decision \\
\hline MPIPC & $>2$ & $\mathrm{R}$ \\
ABK & 0.5 & $\mathrm{~S}$ \\
GM & $>8$ & $\mathrm{R}$ \\
CLDM & $\leq 0.12$ & $\mathrm{~S}$ \\
MINO & 0.25 & $\mathrm{~S}$ \\
VCM & $\mathrm{I}$ & $\mathrm{S}$ \\
TEIC & $\mathrm{I}$ & $\mathrm{S}$ \\
LZD & $\mathrm{I}$ & $\mathrm{S}$ \\
ST & $\leq 5$ & $\mathrm{~S}$ \\
LVFX & $\leq 0.12$ & $\mathrm{~S}$ \\
\hline
\end{tabular}

Abbreviations: ABK, arbekacin; CLDM, clindamycin; GM, gentamicin; LVFX, levofloxacin; LZD, linezolid; MINO, minocycline; MPIPC, oxacillin; R, resistant; $S$, susceptible; ST, sulfamethoxazole-trimethoprim; TEIC, teicoplanin; VCM, vancomycin.

Table 2 Methicillin-resistant Staphylococcus aureus genome analysis

\begin{tabular}{|l|l|}
\hline mecA & + \\
\hline SCCmec & IV \\
mec gene complex & Class B \\
$\quad c c r$ gene complex & $c c r 2$ \\
PVL & - \\
ET & - \\
TSST-I & + \\
\hline
\end{tabular}

Abbreviations: ET, exfoliative toxin; PVL, Panton-Valentine leukocidin; SCC staphylococcal cassette chromosome; TSST-I, toxic shock syndrome toxin-I. disease, ${ }^{17}$ and the ET toxin causes extensive burn-like epidermal detachment such as staphylococcal scalded skin syndrome. ${ }^{18}$ Although there are limited cases of acute epiglottitis caused by MRSA, ${ }^{19-22}$ an adult case of acute epiglottitis caused by CA-MRSA of a PVL-positive SCCmec type IV clone was reported in the USA. ${ }^{19}$ The majority of Japanese CA-MRSA strains are PVL-negative and TSST-1-positive SCCmec type IV clones, which do not produce PVL and ET and, as such, differ widely from the strains prevalent in the USA and Europe. ${ }^{7}$ In our case, acute epiglottitis in an infant was caused by PVL-negative and TSST-1-positive SCCmec type IV MRSA. The TSST-1-positive SCCmec type II clone is known as a New York/Japan clone. ${ }^{7}$ On the other hand, the TSST-1-positive SCCmec type IV clone is frequently found in Japan. ${ }^{7}$ In the current case, acute epiglottitis was caused by a CA-MRSA, which is rare in Japan.

In our patient, blood culture was negative, but MRSA was directly detected from the site of adhesion of exudate on the posterior pharyngeal wall. It is surprising that a 17-day-old infant with a normal immune status carried CA-MRSA and MRSA-caused acute epiglottitis. In Iceland and Denmark, the Hib vaccine was introduced $10-20$ years before its introduction in Japan. In Iceland, vaccination against Hib diseases began in 1989 where epiglottitis is cause by $H$. influenzae (17\%), Streptococcus sp. (15\%), and Sta. aureus (2\%). ${ }^{3}$ In Denmark, the Hib vaccine was started in 1998, and Streptococcus sp. was responsible for $26 \%$, H. influenza for $7 \%$, and Sta. aureus for $7 \%$ of acute epiglottitis cases. ${ }^{4} \mathrm{H}$. influenzae is still a causative bacterium in Iceland and Denmark, but the proportion of acute epiglottitis cases caused by $H$. influenzae is low. Thus, in the post-Hib vaccine era, pediatricians and physicians should consider bacteria other than $H$. influenza, such as Streptococcus and Staphylococcus sp. including MRSA, as a cause of acute epiglottitis. Currently, as immunization against Hib has become widespread in Japan, CAMRSA also should be considered a causative organism for acute epiglottitis. When CA-MRSA is a causative organism, it is necessary to select the appropriate antibiotics.

Streptococcus pyogenes, Epstein-Barr virus, and adenovirus are well-known causes of upper respiratory tract infection with exudate. In the current case, the presence of exudate around the epiglottis from the posterior pharyngeal wall was a characteristic feature of acute epiglottitis. Our PubMed search revealed four cases of acute epiglottis caused by MRSA, of which two cases showed the presence of exudates. ${ }^{19,22}$ Sta. aureus including MRSA is not the main organism causing upper respiratory tract infection with exudates; however, it is a possible causative organism. 


\section{Conclusion}

To the best of our knowledge, this is a first case of acute epiglottitis caused by MRSA with a PVL-negative and TSST-1-positive SCCmec type IV clone, which is a CA-MRSA in Japan. CA-MRSA should be considered a causative organism for acute epiglottitis in the post-Hib vaccine era. Further observations with a large patient population are needed to confirm a causative organism in the post-Hib vaccine era in Japan.

\section{Consent for publication}

We obtained written informed consent including data and images for publication from the guardian of the patient.

\section{Data sharing statement}

The data used in this report are available from the corresponding author on reasonable request.

\section{Acknowledgment}

This research is partially supported by the Japan Agency for Medical Research and Development (grant number: 18fk0108047h0002) and the Kawano Masanori Memorial Foundation for Promotion of Pediatrics.

\section{Author contributions}

All authors contributed to the intellectual content of this manuscript and approved the final manuscript as submitted. JF and IM drafted the initial manuscript. JF, TM, KK, and NS cared for the patient and collected the clinical samples or data. DO and TY performed genome analysis. All authors interpreted the data and revised the article critically for important intellectual content.

\section{Disclosure}

Outside the submitted work, IM has received grants from Japan Blood Product Organization, Daiichi Sankyo Co., Ltd, MSD Co., Ltd, AbbVie LLC, Taisho Toyama Pharmaceutical Co., Ltd, and Air Water Inc. IM also received lecture fees from MSD Co., Ltd, Pfizer Japan, Inc., Novo Nordisk Pharma Ltd, Shionogi Co., Ltd, AbbVie LLC, Japan Vaccine Co., Ltd, Asahikasei Medical Co., Ltd, and Atom Medical Corp., as well as manuscript fees from Atom Medical Corp., Sanofi K.K., Asahikasei Medical Co., Ltd, and Japan Blood Product Organization and honoraria from Sanofi K.K. The authors report no other conflicts of interest in this work.

\section{References}

1. González Valdepeña H, Wald ER, Rose E, Ungkanont K, Casselbrant ML. Epiglottitis and Haemophilus influenzae immunization: the Pittsburgh experience - a five-year review. Pediatrics. 1995;96(3 Pt 1):424 427.
2. Shah RK, Stocks C. Epiglottitis in the United States: national trends, variances, prognosis, and management. Laryngoscope. 2009;120(6):1256-1262.

3. Briem B, Thorvardsson O, Petersen H. Acute epiglottitis in Iceland 1983-2005. Auris Nasus Larynx. 2009;36(1):46-52.

4. Kjaerulff AMG, Rusan M, Klug TEMarlene A, Ehlers T. Clinical evaluation of intravenous ampicillin as empirical antimicrobial treatment of acute epiglottitis. Acta Otolaryngol. 2018;138(1):1-6.

5. Sakata H, Adachi Y, Morozumi M, Ubukata K. Invasive Haemophilus influenzae infections in children in Kamikawa subprefecture, Hokkaido, Japan, 2006-2015: The effectiveness of H. influenzae type b vaccine. $J$ Infect Chemother. 2017;23(7):459-462.

6. Kondo Y, Ito T, Ma XX, et al. Combination of multiplex PCRs for staphylococcal cassette chromosome mec type assignment: rapid identification system for $m e c$, ccr, and major differences in junkyard regions. Antimicrob Agents Chemother. 2007;51(1):264-274.

7. Yamaguchi T, Okamura S, Miura Y, Koyama S, Yanagisawa H, Matsumoto T. Molecular characterization of community-associated methicillin-resistant Staphylococcus aureus isolated from skin and pus samples of outpatients in Japan. Microb Drug Resist. 2015;21(4):441-447.

8. International Working Group on the Classification of Staphylococcal Cassette Chromosome Elements. Classification of staphylococcal cassette chromosome mec (SCCmec): guidelines for reporting novel SCCmec elements. Antimicrob Agents Chemother. 2009;53(12):4961-4967.

9. Ito T, Kuwahara-Arai K, Katayama Y, et al. Staphylococcal Cassette Chromosome mec (SCCmec) analysis of MRSA. Methods Mol Biol. 2014;1085:131-148.

10. Ma XX, Ito T, Chongtrakool P, Hiramatsu K. Predominance of clones carrying Panton-Valentine leukocidin genes among methicillin-resistant Staphylococcus aureus strains isolated in Japanese hospitals from 1979 to 1985. J Clin Microbiol. 2006;44(12):4515-4527.

11. Reva I, Higuchi W, Takano T, et al. A rapid screening method for PantonValentine leucocidin-positive community-acquired methicillin-resistant Staphylococcus aureus belonging to multilocus sequence type 30 and its related clone using a combination of multiplex PCR and pulsed-field gel electrophoresis. J Infect Chemother. 2009;15(2):75-83.

12. Yamaguchi T, Nishifuji K, Sasaki M, et al. Identification of the Staphylococcus aureus etd pathogenicity island which encodes a novel exfoliative toxin, ETD, and EDIN-B. Infect Immun. 2002;70(10):5835-5845.

13. Yamaguchi T, Yokota Y, Terajima J, et al. Clonal association of Staphylococcus aureus causing bullous impetigo and the emergence of new methicillin-resistant clonal groups in Kansai district in Japan. $J$ Infect Dis. 2002;185(10):1511-1516.

14. Baig S, Johannesen TB, Overballe-Petersen S, Larsen J, Larsen AR, Stegger M. Novel SCCmec type XIII (9A) identified in an ST152 methicillinresistant Staphylococcus aureus. Infect Genet Evol. 2018;61:74-76.

15. Monecke S, Coombs G, Shore AC, et al. A field guide to pandemic, epidemic and sporadic clones of methicillin-resistant Staphylococcus aureus. PLoS One. 2011;6(4):e17936.

16. David MZ, Daum RS. Community-associated methicillin-resistant Staphylococcus aureus: epidemiology and clinical consequences of an emerging epidemic. Clin Microbiol Rev. 2010;23(3):616-687.

17. Takahashi N. Neonatal toxic shock syndrome-like exanthematous disease (NTED). Pediatr Int. 2003;45(2):233-237.

18. Nakaminami H, Noguchi N, Ikeda M, et al. Molecular epidemiology and antimicrobial susceptibilities of 273 exfoliative toxin-encoding-genepositive Staphylococcus aureus isolates from patients with impetigo in Japan. J Med Microbiol. 2008;57(Pt 10):1251-1258.

19. Young LS, Price CS. Complicated adult epiglottitis due to methicillinresistant Staphylococcus aureus. Am J Otolaryngol. 2007;28(6):441-443.

20. Freeman L, Wolford R. Acute epiglottitis caused by methicillin-resistant Staphylococcus aureus in adults. Clin Infect Dis. 1998;26(5):1240-1241.

21. Noble J, Devor R, Rogalski FJ, Vergara W, Reddy RP, Bhumbra N. Aphonia and epiglottitis in neonate with concomitant MRSA skin infection. Respirol Case Rep. 2014;2(3):116-119.

22. Somenek M, Le M, Walner DL. Membranous laryngitis in a child. Int J Pediatr Otorhinolaryngol. 2010;74(6):704-706. 
Infection and Drug Resistance is an international, peer-reviewed openaccess journal that focuses on the optimal treatment of infection (bacterial, fungal and viral) and the development and institution of preventive strategies to minimize the development and spread of resistance. The journal is specifically concerned with the epidemiology of antibiotic resistance and the mechanisms of resistance development and diffusion in both hospitals and the community. The manuscript management system is completely online and includes a very quick and fair peerreview system, which is all easy to use. Visit http://www.dovepress.com/ testimonials.php to read real quotes from published authors.

Submit your manuscript here: https://www.dovepress.com/infection-and-drug-resistance-journal 